\title{
Article \\ Coffee Silverskin as a Multifunctional Waste Filler for High-Density Polyethylene Green Composites
}

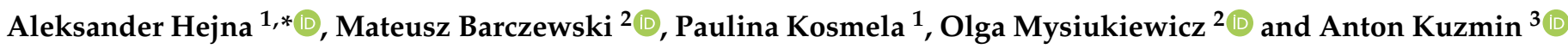 \\ 1 Department of Polymer Technology, Gdańsk University of Technology, Narutowicza 11/12, \\ 80-233 Gdańsk, Poland; paulina.kosmela@pg.edu.pl \\ 2 Institute of Materials Technology, Poznan University of Technology, Piotrowo 3, 61-138 Poznań, Poland; \\ mateusz.barczewski@put.poznan.pl (M.B.); olga.mysiukiewicz@put.poznan.pl (O.M.) \\ 3 Mechanics and Power Engineering Institute, Ogarev Mordovia State University, 68 Bolshevistskaya Str., \\ 430005 Saransk, Russia; kuzmin.a.m@yandex.ru \\ * Correspondence: aleksander.hejna@pg.gda.pl
}

Citation: Hejna, A.; Barczewski, M.; Kosmela, P.; Mysiukiewicz, O.;

Kuzmin, A. Coffee Silverskin as a Multifunctional Waste Filler for High-Density Polyethylene Green Composites. J. Compos. Sci. 2021, 5 , 44. https://doi.org/10.3390/ jcs5020044

Academic Editor:

Francesco Tornabene

Received: 6 January 2021

Accepted: 26 January 2021

Published: 1 February 202

Publisher's Note: MDPI stays neutral with regard to jurisdictional claims in published maps and institutional affiliations.

Copyright: (c) 2021 by the authors. Licensee MDPI, Basel, Switzerland. This article is an open access article distributed under the terms and conditions of the Creative Commons Attribution (CC BY) license (https:// creativecommons.org/licenses/by/ $4.0 /)$.

\begin{abstract}
This work aims to describe the coffee silverskin effect as a lignocellulosic waste filler for high-density polyethylene (HDPE) composites development. The main task was to determine various modification effects resulting from the complex chemical composition of coffee silverskin containing compounds with potential antioxidative properties, including caffeine, polyphenols, tannins, or melanoidins. The processing, thermal, physicochemical, and thermomechanical properties of the HDPE-based composites with different filler content (1-20 wt $\%$ ) were evaluated. Comprehensively realized thermomechanical analysis revealed the filler's reinforcing effects on the HDPE matrix while defining problems with obtaining adequate adhesion in the interfacial area. At the same time, studies have shown a very beneficial effect of the silverskin addition on the thermal properties of composites, that even the smallest addition allows for a significant increase in the thermooxidative resistance of HDPE composites assessed using the oxidation induction time from $20 \mathrm{~min}$ for HDPE up to $140 \mathrm{~min}$ for the composites with $20 \mathrm{wt} \%$ of the filler. The obtained research results allow classifying the coffee silverskin waste filler, not only as a filler intended for the production of composites with a high degree of filling but also as an additive that significantly changes the properties of polyethylene in the case of using low concentrations. This can have a very beneficial impact on the development of novel wood polymer (WPC) and natural fiber composites (NFC).
\end{abstract}

Keywords: wood-polymer composite; coffee silverskin; recycling; mechanical properties; thermal properties

\section{Introduction}

Nowadays, due to far-reaching consumerism, multiple branches of industry are generating vast amounts of by-products and wastes. Such a phenomenon is also noted in the food industry. According to the Food and Agriculture Organization of the United Nations, the global volume of food wastage is estimated at 1.6 billion tons of "primary product equivalents" [1]. Moreover, significant amounts of non-edible by-products are generated during the processing and manufacturing of various food products. Processing of fruits, such as pineapple, banana, mango, or grapes generates from 30 to even $45 \mathrm{wt} \%$ of by-products. Production of one hectoliter of beer generates almost $7 \mathrm{~kg}$ of brewers' spent grain-solid lignocellulose waste [2]. However, the coffee industry may be considered as one of the record holders. During roasted coffee manufacturing, over $50 \mathrm{wt} \%$ of the fresh coffee cherry is discarded and treated as waste [3].

Considering the global production volume in the food sector, huge amounts of byproducts are generated and often not recycled [4,5]. From the above-mentioned 1.6 billion tons of food waste, reported by the Food and Agriculture Organization of the United Nations, 38\%, over 600 million tons is generated during food processing [6]. One of the 
possible ways of their utilization is its application in the polymer technology [7]. Keeping in mind the ongoing trends and law regulations related to polymers' environmental impact, the application of food industry by-products may also reduce the use of synthetic compounds [8-10]. Besides, incorporating raw materials from natural sources may be used to prepare biodegradable substitute for conventional polymer materials [11]. However, what we believe is most important is that most of these by-products, especially considering plant-based lignocellulose materials, may be incorporated into polymer technology, mainly as functional fillers for polymer composites and as antioxidants, antimicrobial agents, plasticizers, or colorants [12-14].

Considering the additional value, promising materials are coffee industry by-products, especially coffee silverskin. This material is generated during the roasting of green coffee [15]. Therefore, contrary to most coffee industry by-products, coffee silverskin is characterized by very low moisture content, which makes it a ready-to-use material [16]. Its potential application in polymer technology may require additional grinding. However, this is common for all types of materials. Considering composition, coffee silverskin is similar to other types of lignocellulose materials introduced into polymer technology. Except for the fiber content, silverskin usually contains $15-19 \mathrm{wt} \%$ of proteins, but mostly it is a rich source of compounds with antioxidant activity [17]. This by-product is an excellent source of caffeine, polyphenols, tannins, or melanoidins, which result in high antioxidant activity, even up to $18 \mu \mathrm{mol} \mathrm{TR} / \mathrm{g}$ [18]. These compounds could also be considered very interesting to enhance polymer materials' resistance towards oxidation [19].

Nevertheless, despite the high potential of the coffee silverskin to act not only as a conventional filler, but also as functional additive for wood-polymer composites, the majority of research works related to the use of this by-product in polymer technology still focuses mainly on morphology and basic mechanical and thermal performance with-out a deeper analysis of the additional effects [20-23]. The authors of these works agreeably reported that coffee silverskin increased the stiffness of polymer matrices and their crystallinity. Moreover, in the case of some polymer matrices, e.g., poly(butylene succinate) or poly(butylene adipate-co-terephthalate/poly(3-hydroxybutyrate-co-3-hydroxyvalerate), the increase in tensile strength was noted. However, this effect was not observed for stronger poly(lactic acid) [23]. These works implicated also the need of coffee silverskin modification or compatibilization to noticeably improve the mechanical performance and to allow the silverskin to act as "true" reinforcement. Only one work of Zarrinbakhsh et al. [24] reported the changes in processing of polymer composites expressed by the melt flow index value. Considering the antioxidant activity of coffee silverskin, only Sarasini et al. [25] investigated the DPPH scavenging activity of the extracts prepared from composites. However, there are no reports on the impact of coffee silverskin on thermooxidative stability of composites.

Presented research work aimed to investigate the influence of coffee silverskin and its loading (1-20 wt\%) on the processing (melt flow index), physico-mechanical (density, static and dynamic mechanical properties), and thermal (melting and crystallization behavior, oxidation induction time) performance of polyethylene-based composites.

\section{Materials and Methods}

\subsection{Materials}

High-density polyethylene (HDPE), type M300054, obtained from SABIC (Sittard, The Netherlands), was applied as a matrix to prepare investigated composites. According to producer data, its density equaled $0.954 \mathrm{~g} / \mathrm{cm}^{3}$, and it was characterized by a melt flow rate of $30 \mathrm{~g} / 10 \mathrm{~min}\left(190^{\circ} \mathrm{C}, 2.16 \mathrm{~kg}\right)$. Coffee silverskin (ŁK) was obtained from the local coffee roastery. Before introducing it into polyethylene, it was grounded using Retsch GM 200 knife grinder (Haan, Germany) and sieved using Fritsch Analysette 22 sieve shaker with $400 \mu \mathrm{m}$ mesh (Weimar, Germany). In Figure 1, there are photographs shown of applied filler before and after grinding. The chemical composition of coffee silverskin according to different literature reports was presented in latest review work [26]. Generally, this by-product contains from 53 to $74 \mathrm{wt} \%$ (of dry matter) of fiber, including 48 to $67 \mathrm{wt} \%$ of 
insoluble ones, hence cellulose, hemicellulose, and lignin [27-29]. As mentioned above, coffee silverskin also contains $15-19 \mathrm{wt} \%$ of proteins [17,30]. Moreover, $5.0-7.5 \mathrm{wt} \%$ of ash and even $1.4 \mathrm{wt} \%$ of caffeine were reported [31,32].

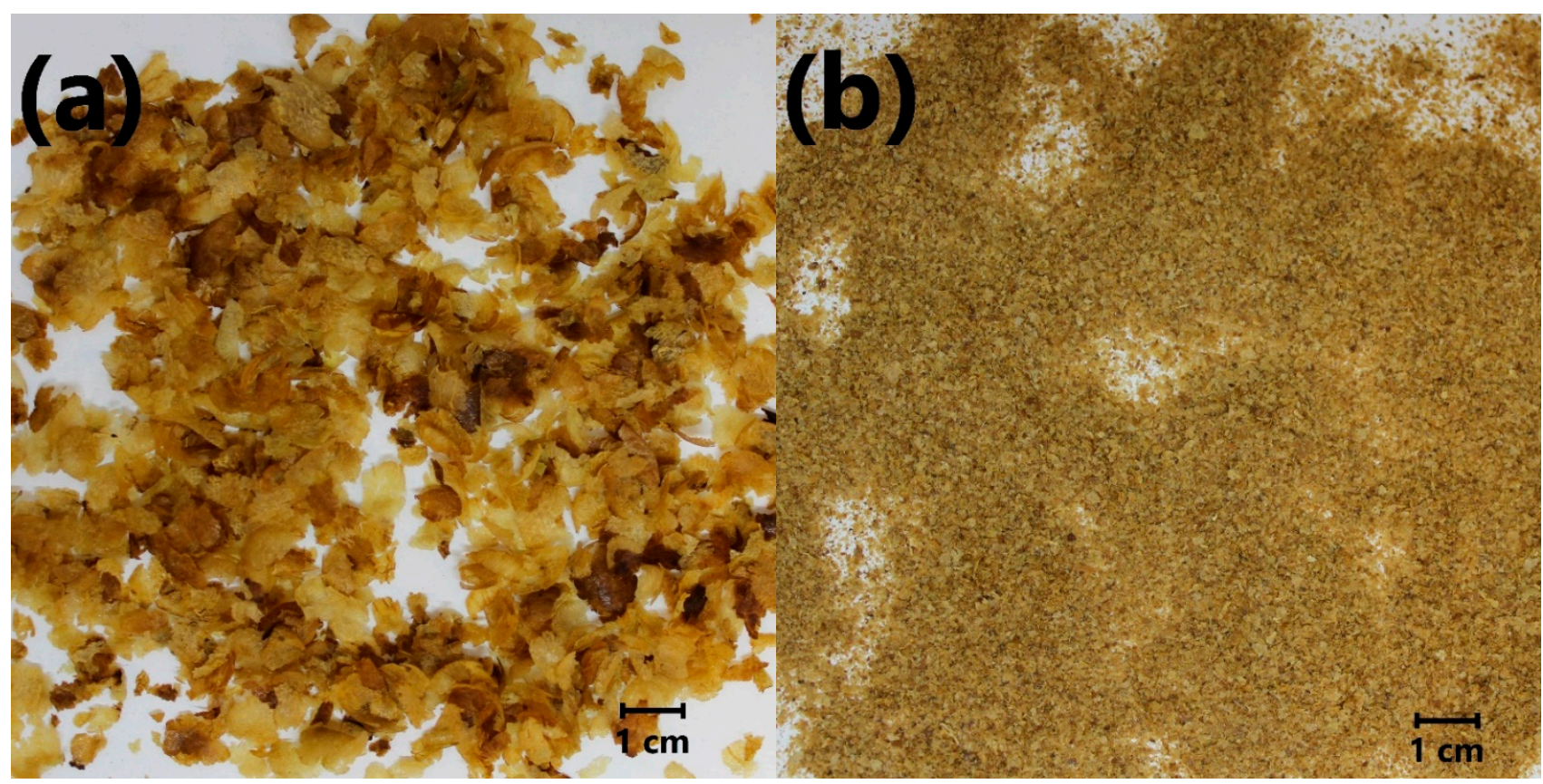

Figure 1. The appearance of the applied coffee silverskin (a) before and (b) after grinding.

\subsection{Preparation of Polymer Composites}

The composites were prepared by mixing in a molten state. The HDPE pellets were pulverized into a fine powder using a Tria 25-16/TC-SL high-speed knife grinder (Charlotte, $\mathrm{NC}, \mathrm{USA}$ ) to facilitate the mixing process. The polymeric powder was then preliminary mixed with $1,2,5,10$, or $20 \mathrm{wt} \%$ of fillers. Preliminary to mixing in molten state compositions were dried in laboratory cabined dryer Memmert ULE 500 (Schwabach, Germany) for $12 \mathrm{~h}$ at $70{ }^{\circ} \mathrm{C}$. The mixtures were processed using a ZAMAK EH16.2D co-rotating twinscrew extruder (Skawina, Poland), with a screw diameter of $\mathrm{D}=16 \mathrm{~mm}$, length to diameter ratio $\mathrm{L} / \mathrm{D}=40$, and capillary die with diameter $\mathrm{d}=8 \mathrm{~mm}$. The processing was realized at a constant screw rotary speed of $100 \mathrm{rpm}$, and the plastifying unit's temperature profiles follow 190-185-185-180-175-165-160-145 ${ }^{\circ} \mathrm{C}$. Configuration of the functional screw segments was presented and discussed in our previous studies [33]. The obtained materials were cooled in forced airflow and pelletized. The resulting composites were then compression molded at $170{ }^{\circ} \mathrm{C}$ and $4.9 \mathrm{MPa}$ for $2 \mathrm{~min}$, then kept under pressure at room temperature for another $5 \mathrm{~min}$ to solidify the material, and freely cool down in a room temperature conditions. The unfilled HDPE was processed along with its composites. The specimens were named in reference to their filler content, like PE and PE/XŁK, where $X$ stands for the filler content.

\subsection{Characterization Techniques}

Melt flow index (MFI) of the composites was investigated using Zwick mFlow plastometer (Ulm, Germany) according to ISO 1133 standard $\left(190{ }^{\circ} \mathrm{C}, 2.16 \mathrm{~kg}\right)$. Samples of $6 \mathrm{~g}$ were used.

The specific weight of applied filler and resulting composites was determined using Ultrapyc 5000 Foam gas pycnometer from Anton Paar (Austria). The following measurement settings were applied: Gas-helium; target pressure-10.0 psi (for filler) and $18.0 \mathrm{psi}$ (for composites); flow direction—sample first; temperature control—on; target temperature $-20.0^{\circ} \mathrm{C}$; flow mode-fine powder (for filler) and monolith (for composites); 
cell size—small, $10 \mathrm{~cm}^{3}$; preparation mode—pulse, five pulses (for filler) and flow, $0.5 \mathrm{~min}$ (for composites); the number of runs-5.

The tensile strength and elongation at break were estimated following ISO 527 for dumbbell samples type 5B. Dimensions of samples were as follows: Width of narrow parallel-sided portion: $2 \mathrm{~mm}$; width at ends: $6 \mathrm{~mm}$; thickness: $1 \mathrm{~mm}$; gauge length: $10 \mathrm{~mm}$; length of narrow parallel-sided portion: $12 \mathrm{~mm}$; overall length: $35 \mathrm{~mm}$. Tensile tests were performed on a Zwick/Roell Z020 apparatus (Ulm, Germany) with a cell load capacity of $20 \mathrm{kN}$ at a constant speed of $5 \mathrm{~mm} / \mathrm{min}$. At least five specimens for each sample were analyzed.

The dynamic mechanical analysis was conducted on a DMA Q800 TA Instruments apparatus (TA Instruments, New Castle, DE, USA). Samples with dimensions of $40 \times 10 \times 2 \mathrm{~mm}$ were loaded with variable sinusoidal deformation forces in the single cantilever bending mode at the frequency of $1 \mathrm{~Hz}$ under the temperature rising rate of $4{ }^{\circ} \mathrm{C} / \mathrm{min}$, ranging the temperature from -100 to $100^{\circ} \mathrm{C}$. Two specimens for each sample were analyzed.

Oxidation induction time (OIT) of analyzed composites was determined by the differential scanning calorimetry (DSC) analysis. The $5 \mathrm{mg}$ samples were placed in aluminum crucibles with pierced lids. They were heated from 20 to $190{ }^{\circ} \mathrm{C}$ with a heating rate of $20^{\circ} \mathrm{C} / \mathrm{min}$ in nitrogen, then kept at $190^{\circ} \mathrm{C}$ for $5 \mathrm{~min}$ in nitrogen, and then gas was switched to oxygen, and the time required for sample oxidation was measured. The measurements were conducted using a Netzsch 204F1 Phoenix apparatus (Selb, Germany).

To determine the crystallization and melting temperatures, as well as the crystalline structure of analyzed composites, DSC analysis was applied. The $5 \mathrm{mg}$ samples were placed in aluminum crucibles with pierced lids. They were heated from 20 to $250{ }^{\circ} \mathrm{C}$ with a heating rate of $10^{\circ} \mathrm{C} / \mathrm{min}$ and then cooled back to the initial temperature with a cooling rate of $10^{\circ} \mathrm{C} / \mathrm{min}$. The heating/cooling cycle was performed twice to erase the polymers' thermal history during the first heating. The measurements were conducted using a Netzsch 204F1 Phoenix apparatus (Selb, Germany) in an inert atmosphere of nitrogen. The crystallinity degree $\left(X_{\mathrm{cr}}\right)$ of the samples was calculated using Formula (1):

$$
\mathrm{X}_{\mathrm{cr}}=\left(\Delta \mathrm{H}_{\mathrm{m}} /\left((1-\theta) \cdot \Delta \mathrm{H}_{\mathrm{m} 100 \%}\right)\right) \cdot 100 \%
$$

where $\Delta \mathrm{H}_{\mathrm{m}}$-melting enthalpy of a sample, $\Delta \mathrm{H}_{\mathrm{m} 100 \%}$-melting enthalpy of $100 \%$ crystalline polyethylene, equal to $293.6 \mathrm{~J} / \mathrm{g}$ [34], $\theta$-filler weight fraction.

Results of DSC analysis were also used to calculate the value of the supercooling parameter presented by Qiu et al. [35] according to the following Equation (2):

$$
\Delta \mathrm{T}=\mathrm{Tm}-\mathrm{Tc}
$$

where $\mathrm{T}_{\mathrm{m}}$-melting temperature, ${ }^{\circ} \mathrm{C} ; \mathrm{T}_{\mathrm{c}}-$ crystallization temperature, ${ }^{\circ} \mathrm{C}$.

\section{Results and Discussion}

\subsection{Melt Flow Index of Prepared Composites}

Figure 2 presents the results of the melt flow analysis of prepared composite materials. It can be seen that the incorporation of the coffee silverskin into the polyethylene matrix reduced the flowability of analyzed materials. Such an effect is often noted for polymer composites [36]. Nevertheless, for lower filler loadings, up to $5 \mathrm{wt} \%$, changes were not very significant, therefore not suppressing the composites' processability compared to unmodified HDPE. The limited negative effect of the lignocellulosic filler observed for lower filler content may be related to the uniform distribution of the filler and the content of proteins, which may act to a certain extent as plasticizers [37]. Further increase in ŁK content caused a significant drop in mass and volumetric melt flow index. It was associated with the noticeable rise of melt viscosity due to polymer macromolecules' limited mobility [38]. Moreover, the significant rise of viscosity for 10 and $20 \mathrm{wt} \% € K$ loading suggests achieving the rheological percolation threshold and the presence of agglomerates of coffee silverskin particles [39]. The significant reduction of composites' flowability, measured as changes of 
MFR and MVR may significantly deteriorate the processing properties of final compositions, including limited quality of the injection molded parts in the form of short shots and increased surface roughness.

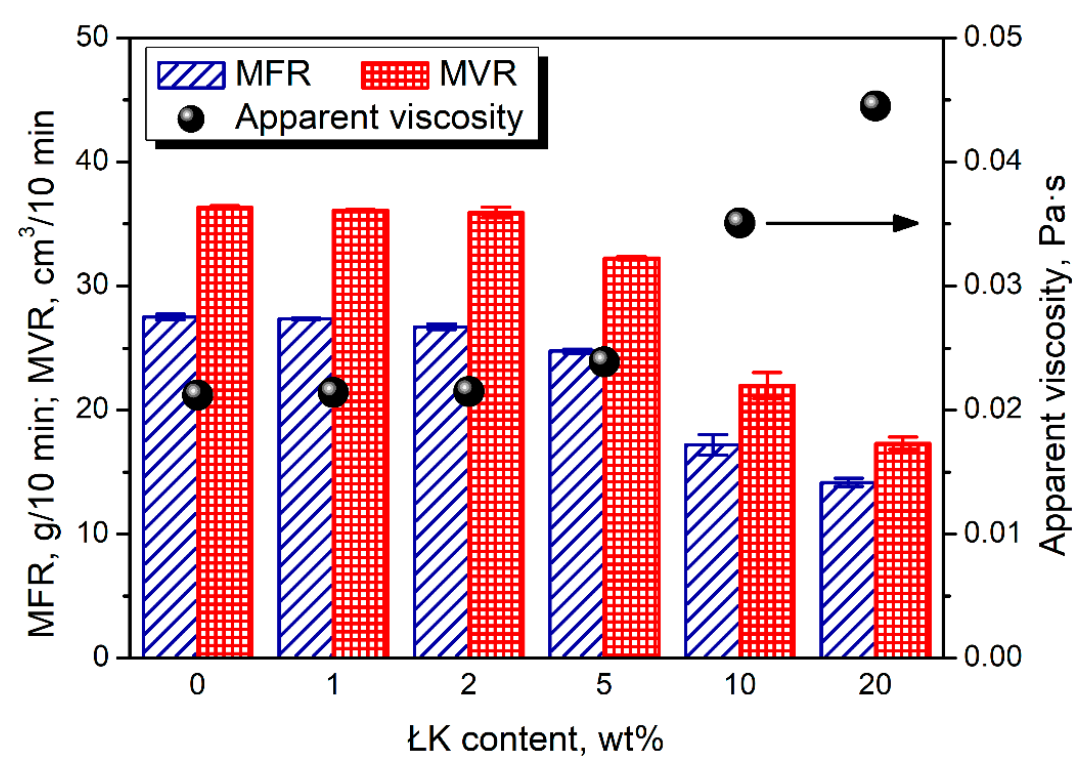

Figure 2. Results of the melt flow analysis of prepared PE/ŁK composites.

\subsection{Physico-Mechanical Performance of Prepared Composites}

Figure 3 presents the values of composites density and porosity depending on the mass and volume content of the $Ł K$ filler. The rise of theoretical and experimental values of density and lower volume contents of filler than mass contents are related to the higher density of filler $\left(1.4103 \mathrm{~g} / \mathrm{cm}^{3}\right)$ than the polyethylene matrix $\left(0.9435 \mathrm{~g} / \mathrm{cm}^{3}\right)$. This effect is commonly observed for polymer composites because most polymer matrix densities are often noticeably lower than most natural, mainly mineral fillers [40]. It is especially pronounced for polyethylene and polypropylene, which have a lower specific weight than water, which is very important for their potential applications and further recycling [41]. Such a phenomenon significantly facilitates recycling polyolefins because they can often be easily separated from other plastics.

ŁK volume content, vol\%

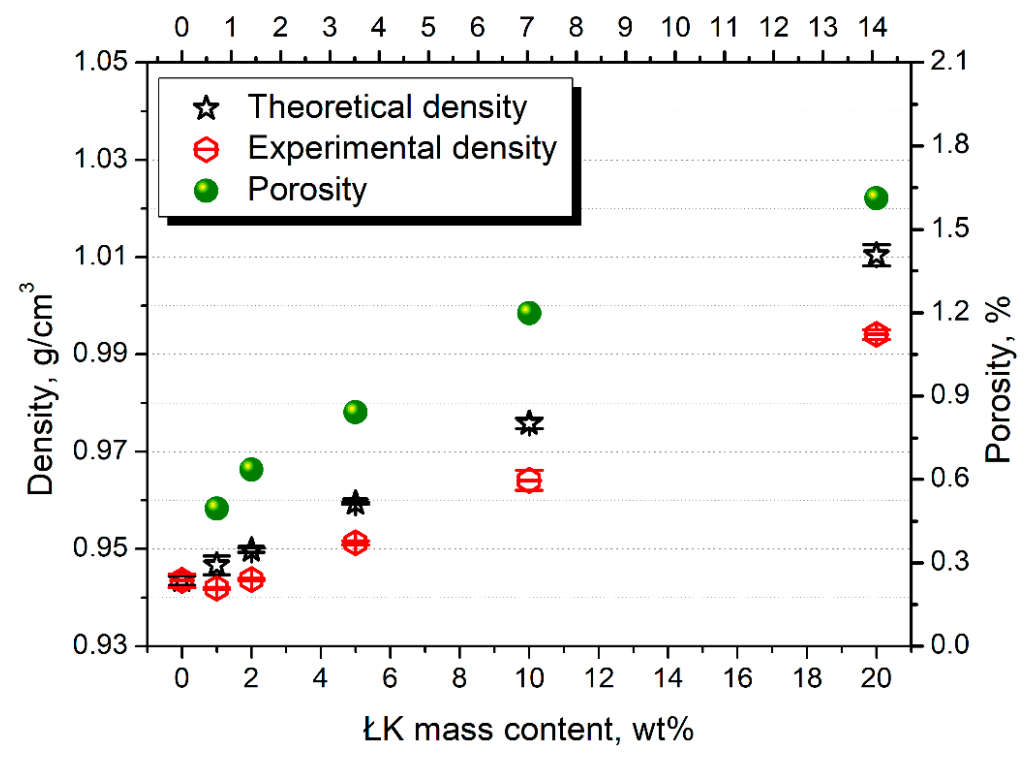

Figure 3. The theoretical and experimental density of composites and calculated porosity values. 
Noticeable differences were noted between measured, experimental values of composites' density and theoretical ones, calculated according to the following Equation (3):

$$
\rho_{\mathrm{c}}=\rho_{\mathrm{m}} \cdot(1-\phi)+\rho_{\mathrm{f}} \phi
$$

where $\rho_{\mathrm{c}}$-density of the composite, $\mathrm{g} / \mathrm{cm}^{3} ; \rho_{\mathrm{m}}$-density of the matrix, $\mathrm{g} / \mathrm{cm}^{3} ; \rho_{\mathrm{f}}$-density of the filler, $\mathrm{g} / \mathrm{cm}^{3} ; \phi-$ volume fraction of the filler.

Such an effect can be associated with the imperfect encapsulation of the ŁK filler particles by polyethylene matrix, associated with the air inclusions during processing and agglomeration of particles, especially at higher loadings. As a result, voids at the interface were generated, resulting in the porosity of the material. Such an effect is often observed during the preparation of polymer composites [40,42,43]. It may noticeably affect the performance of composite materials [44]. Differences between theoretical and experimental values of density enabled the quantitative determination of composites' porosity using the following Equation (4):

$$
\mathrm{p}=\left(\rho_{\text {theo }}-\rho_{\text {exp }}\right) / \rho_{\text {theo }} \cdot 100 \%
$$

where $\mathrm{p}$-porosity of the material, \%; $\rho_{\text {theo }}$-theoretical value of density, $\mathrm{g} / \mathrm{cm}^{3}$; and $\rho_{\text {exp }}$-the experimental value of density of composite, $\mathrm{g} / \mathrm{cm}^{3}$.

The composites' porosity is slightly increasing with the filler loading. However, its values are below $1.7 \%$ for all samples. Nevertheless, such an effect is not considered very beneficial for the composite materials and points to the need to enhance interfacial interactions between matrix and filler [45].

Figure 4 shows the influence of filler content on the tensile performance of prepared $\mathrm{PE} / \mathrm{EK}$ composites. It can be seen that at lower loadings of the coffee silverskin up to $5 \mathrm{wt} \%$, tensile strength was maintained at the same level. Slight enhancement was even noted for 1 and $2 \mathrm{wt} \%$ additions, which resulted in the rise of tensile strength from $21.1 \mathrm{MPa}$ to 22.0 and $22.7 \mathrm{MPa}$, respectively. Significant deterioration was observed only for $20 \mathrm{wt} \%$ filler loading, which resulted in the drop to $15.6 \mathrm{MPa}$. Contrary to tensile strength, elongation at break was very sensitive to the incorporation of filler. This parameter was decreased from the initial $768 \%$ to the values in the range of $4.5-18.4 \%$. Such an effect, related to the introduction of solid particles and loss of continuity of the material, is often observed in polymer composites with natural fillers [46]. It is also particularly pronounced when no additional compatibilizers are included [47].
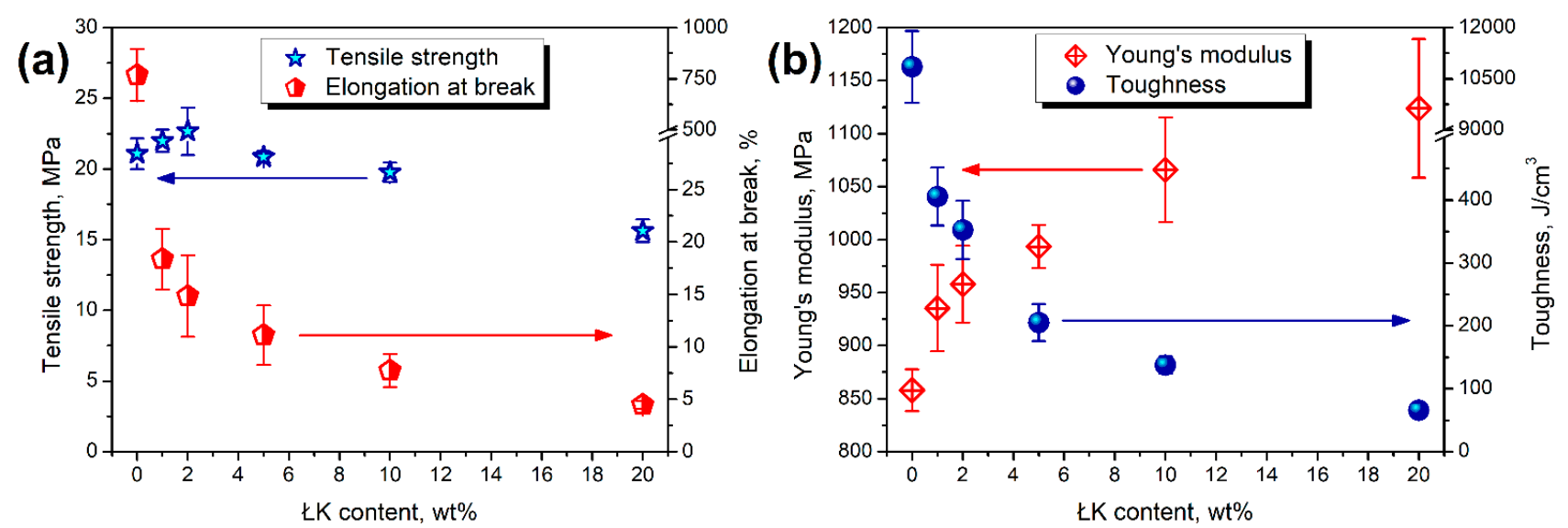

Figure 4. The impact of coffee silverskin content on the (a) tensile strength and elongation at break, (b) Young's modulus and toughness of prepared composites.

In polymer composites, the ductility drop expressed by the decrease of elongation at break is often caused by the polymer matrix's stiffening. Such an effect is associated with the simultaneously occurring reinforcing effect of rigid lignocellulosic particles and creating the potential micro-notches at the polymer-filler interface. As a result, the rise of 
Young's modulus was noted from the initial $858 \mathrm{MPa}$ to $1124 \mathrm{MPa}$ for $20 \mathrm{wt} \%$ addition of the ŁK filler.

The tensile test results were also used to determine composites' toughness values by integrating stress-strain curves. Toughness represents the total amount of energy absorbed or dispersed by the material [48]. Ideally, tough material should be characterized by high values of tensile strength and elongation at break. For the prepared composites, toughness significantly drops with the ŁK content, which is mostly associated with the drop of elongation at break. As a result, the toughness was decreased by $96.2-99.4 \%$.

The dynamic mechanical analysis was performed for a more detailed analysis of the $€ K$ filler influence on prepared composites' mechanical performance. Its results are presented in Table 1. Values of the storage modulus ( $\left.E^{\prime}\right)$ at room temperature and their increase with the loading of filler confirm tensile tests' results indicate the stiffening of composites' structure. For the quantitative determination of the effectiveness of coffee silverskin on the storage modulus of polymer composites, the $C$ factor was calculated according to the following Equation (5):

$$
\mathrm{C}=\left(\mathrm{E}_{\mathrm{g} \text { comp }}^{\prime} \cdot \mathrm{E}_{\mathrm{r} \text { matrix }}^{\prime}\right) /\left(\mathrm{E}_{\mathrm{r} \text { comp }}^{\prime} \cdot \mathrm{E}_{\mathrm{g} \text { matrix }}^{\prime}\right)
$$

where subscripts $\mathrm{g}$ and $\mathrm{r}$-glassy and rubbery state, subscripts comp and matrix-composites and matrix.

Table 1. Results of the dynamic mechanical analysis of prepared materials.

\begin{tabular}{ccccccc}
\hline \multirow{2}{*}{ Parameter } & \multicolumn{7}{c}{ Sample } \\
\cline { 2 - 7 } & PE & PE/1LK & PE/2ŁK & PE/5ŁK & PE/10ŁK & PE/20ŁK \\
\hline $\mathrm{E}^{\prime}$ at $25^{\circ} \mathrm{C}, \mathrm{MPa}$ & 1637 & 1686 & 1882 & 1967 & 1998 & 2121 \\
$\mathrm{E}^{\prime}$ at $-120^{\circ} \mathrm{C}, \mathrm{MPa}$ & 4372 & 4206 & 4565 & 4662 & 4783 & 5086 \\
$\mathrm{C}$ factor & 1.000 & 0.934 & 0.908 & 0.888 & 0.896 & 0.898 \\
Brittleness, $10^{10} \% \cdot \mathrm{Pa}$ & 0.0080 & 0.3231 & 0.3580 & 0.4572 & 0.6466 & 1.0589 \\
$\mathrm{E}^{\prime \prime}$ at $25^{\circ} \mathrm{C}, \mathrm{MPa}$ & 103.6 & 99.8 & 108.9 & 114.2 & 115.3 & 120.6 \\
$\tan \delta$ at $25^{\circ} \mathrm{C}$ & 0.0633 & 0.0592 & 0.0581 & 0.0577 & 0.0579 & 0.0570 \\
$\mathrm{~A}$ factor at $25^{\circ} \mathrm{C}$ & - & -0.0586 & -0.0696 & -0.0566 & -0.0179 & 0.0507 \\
$\mathrm{~T}_{\mathrm{g}}{ }^{\circ} \mathrm{C}$ & -111.0 & -111.8 & -112.2 & -113.1 & -113.4 & -113.9 \\
$\tan \delta$ at $\mathrm{T}_{\mathrm{g}}$ & 0.0495 & 0.0486 & 0.0479 & 0.0465 & 0.0444 & 0.0424 \\
$\mathrm{C}_{\mathrm{V}}, \%$ & 0 & 1.50 & 2.88 & 5.32 & 8.96 & 12.74 \\
$\mathrm{X}_{\mathrm{Cv}}$ & 0 & 1.50 & 1.44 & 1.06 & 0.90 & 0.64 \\
\hline
\end{tabular}

The $C$ factor's decrease indicates the higher effectiveness of filler on the storage modulus of the composite [49]. It can be seen that except for the $1 \mathrm{wt} \%$ loading of filler, $\mathrm{C}$ factor values are quite similar. A slight increase is noted for the highest contents, which may be related to the slight increase of porosity due to air inclusions and coffee silverskin particles' agglomeration. Nevertheless, the $C$ factor values for the investigated composites were relatively high, indicating weak interfacial interactions between the polyethylene matrix and coffee silverskin particles [49]. Without further surface modification to reduce the hydrophilicity of coffee silverskin particles or incorporation of additional compatibilizer, this filler can hardly be considered true reinforcement.

Except for the $C$ factor, the values of composites' storage modulus were used to determine their brittleness according to the Formula (6) presented by Brostow et al. [50]:

$$
\mathrm{B}=1 /\left(\varepsilon_{\mathrm{b}} \cdot \mathrm{E}^{\prime}\right)
$$

where B-brittleness, $1010 \% \cdot \mathrm{Pa} ; \varepsilon_{\mathrm{b}}$ - elongation at break, $\%$; $\mathrm{E}^{\prime}$-storage modulus at $25^{\circ} \mathrm{C}$, MPa.

The idea of brittleness multicriterial parameter evaluation is quite similar to the toughness, indicating that material with low brittleness should withstand possibly high stress at the possibly widest range of strains. Therefore, brittleness stands reciprocal to toughness. Nevertheless, these parameters are not actually inversely proportional. Even 
though the elongation at break is considered in both cases, toughness takes into account the tensile strength, while brittleness the storage modulus determined by DMA analysis. In their work, Brostow et al. [50] related these two parameters by the rational function. However, we prefer the use of power function, which was also described in our previous work [51], where we connected these parameters by the following Equation (7):

$$
\tau=\mathrm{aB}^{\mathrm{c}}
$$

where $\tau$-toughness, $\mathrm{J} / \mathrm{cm}^{3}$; B-brittleness, $10^{10} \% \cdot \mathrm{Pa}$, a, c-constants.

We believe that this relationship's presentation with power function enables a more straightforward interpretation of the obtained results. The value of a constant determines the base value of composites toughness, while c constant plays a similar level for brittleness. For data presented by Brostow et al. [52], values of a and c are 178.380 and -0.984 , respectively. In the presented work, values of 96.922 and -1.000 were obtained. Most of the experimental data points lie below the literature curve, shown in Figure 5. Such an effect points to the insufficient compatibility of coffee silverskin with polyethylene, caused by the hydrophilic character of filler and hydrophobic character of the matrix. Brostow et al. [52] developed a toughness-brittleness relationship mostly for homopolymers, so no interfacial adhesion was considered. Nevertheless, for 1 and $2 \mathrm{wt} \%$ loadings of $€ K$ filler, data points are very close to the literature curve, pointing to the relatively good interfacial adhesion.

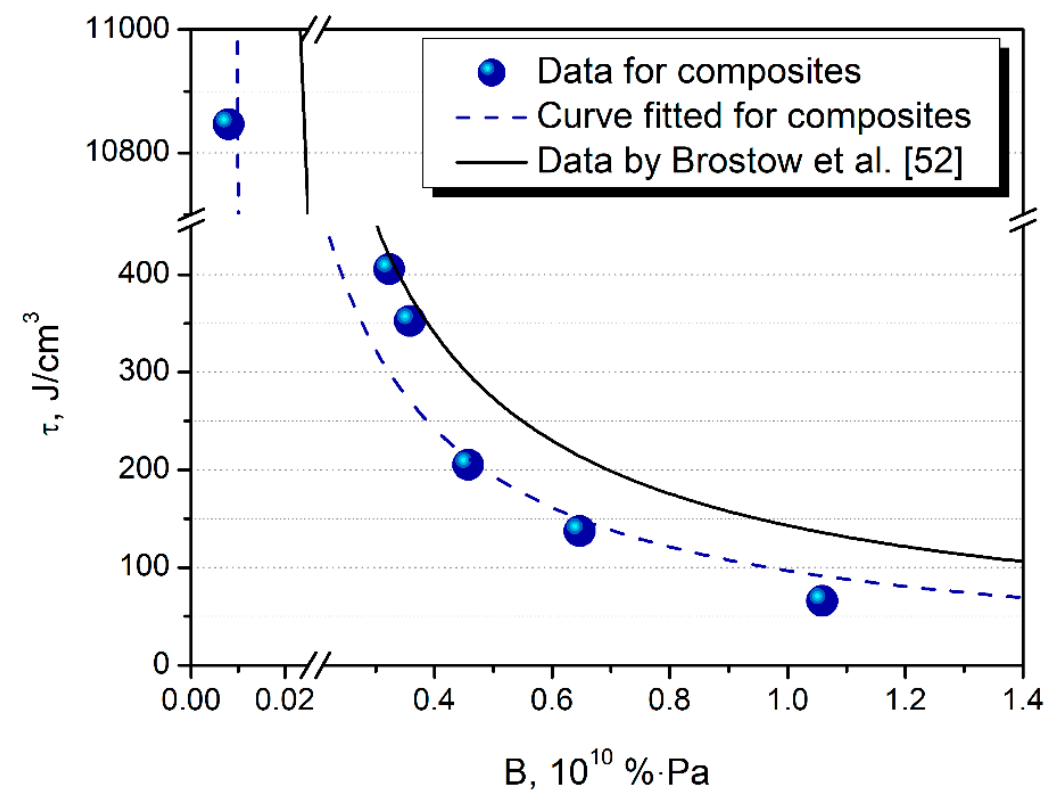

Figure 5. The toughness-brittleness relationship for prepared composites.

Except for the stiffness of materials, the dynamic mechanical analysis may reveal the important insights associated with their damping properties. They are related to the loss tangent $(\tan \delta)$ of material, often called damping factor, because it characterizes a material's ability to dissipate the energy. The decreasing value of loss tangent points to the reduced mobility of polymer macromolecules inside the composites [53]. However, the decrease of $\tan \delta$ was not very significant for analyzed composites, indicating relatively weak interfacial adhesion.

For a more detailed analysis of interfacial interaction, the values of $\tan \delta$ were applied to calculate the adhesion factor, introduced by Kubát et al. [54], following the Formula (8):

$$
\mathrm{A}=(1 / 1-\phi) \cdot\left(\tan \delta_{\text {comp }} / \tan \delta_{\text {matrix }}\right)-1
$$

The adhesion factor can be used to determine the quality of interfacial interactions between matrix and filler. Its lower values indicate enhanced adhesion. Negative values 
are due to the simplifications and assumptions made during calculations, which were described in our previous work [40]. It can be seen that the adhesion factor is decreasing for the lower ŁK loadings up to $2 \mathrm{wt} \%$, which confirms the results mentioned above, e.g., the rise of tensile strength. For $5 \mathrm{wt} \%$ content, the adhesion factor was maintained almost at the same level. Nevertheless, higher loadings resulted in a significant rise of this parameter, pointing to the reduced strength of interfacial interactions. Such an effect can be related to the lack of chemical bonding between phases, followed by the differences in hydrophilicity, as well as the porosity, which generates discontinuity of composites' structure.

The temperature position of $\tan \delta$ peak also provides information on the glass transition temperatures $\left(\mathrm{T}_{\mathrm{g}}\right)$ related to the polymer macromolecules movement changes, which are presented in Table 1. It can be seen that this parameter is slightly decreased with the increasing filler concentration indicating the reduction of free volume in the system and denser polymer packaging.

As mentioned above, the drop of $\tan \delta$ values points to polymer chains' reduced mobility in the composite. Except for the room temperature, values of the loss tangent were also reduced at $\mathrm{T}_{\mathrm{g}}$. According to Bindu et al. [55], these values may be used to determine the number of polymer chains constrained by filler particles using the following formula (9):

$$
\mathrm{C}_{\mathrm{v}}=\left(\left(1-\mathrm{C}_{0}\right) \cdot \mathrm{W}\right) / \mathrm{W}_{0} \cdot 100 \%
$$

where $\mathrm{C}_{\mathrm{v}}$-volume fraction of the immobilized polymer chains, $\% ; \mathrm{C}_{0}$-volume fraction of the immobilized chains in pure polymer (taken to be 0 ), \%; $\mathrm{W}$ and $\mathrm{W}_{0}$-energy loss fractions for the analyzed sample and pure polymer, respectively.

Energy loss fraction $W$ can be calculated from the $\tan \delta$ value following the Equation (10):

$$
\mathrm{W}=(\pi \cdot \tan \delta) /((\pi \cdot \tan \delta)+1)
$$

It can be seen that the $C_{V}$ values are increasing with the loading of filler, but the relationship between these parameters is not directly proportional. In Table 1, there are also presented values of $X_{C_{V}}$, which are quotients of constrained chain volume and $Ł K$ mass content. This parameter's decrease indicates deterioration of the interfacial interactions between filler and matrix, probably caused by the imperfect dispersion and agglomeration of coffee silverskin particles.

\subsection{Thermal Properties of Prepared Composites}

To evaluate coffee silverskin's impact on the resulting composites' thermal properties, differential scanning calorimetry was applied. The results are presented in Table 2. It can be seen that the addition of coffee silverskin did not cause significant changes in the crystallization temperature $\left(\mathrm{T}_{\mathrm{c}}\right)$ of composites. More significant changes were noted for the melting temperature $\left(\mathrm{T}_{\mathrm{m}}\right)$, indicating the decrease in crystallite size due to restrictions related to the presence of solid particles [56]. Values of $T_{c}$ and $T_{m}$ were also used to calculate the supercooling parameter $(\Delta \mathrm{T})$, which is decreasing with the $Ł K$ filler loading, pointing to its nucleating activity [57].

\begin{tabular}{|c|c|c|c|c|c|c|c|}
\hline \multirow{2}{*}{ Sample } & \multicolumn{7}{|c|}{ Parameter } \\
\hline & $\mathrm{T}_{\mathrm{c}},{ }^{\circ} \mathrm{C}$ & $\Delta \mathbf{H}_{\mathrm{c}}, \mathrm{J} / \mathrm{g}$ & $\mathrm{T}_{\mathrm{m}},{ }^{\circ} \mathrm{C}$ & $\Delta H_{m}, J / g$ & $X_{c r}, \%$ & $\Delta \mathrm{T},{ }^{\circ} \mathrm{C}$ & OIT, $\min$ \\
\hline PE & 112.8 & -190.0 & 134.1 & 187.4 & 63.83 & 21.3 & 20.0 \\
\hline PE/1ŁK & 113.1 & -192.8 & 133.2 & 190.5 & 65.54 & 20.1 & 54.8 \\
\hline $\mathrm{PE} / 2 \mathrm{EK}$ & 113.0 & -191.7 & 134.1 & 188.9 & 65.65 & 21.1 & 83.9 \\
\hline PE/5ŁK & 113.3 & -189.4 & 133.3 & 186.5 & 66.87 & 20.0 & 131.9 \\
\hline PE/10ŁK & 113.4 & -178.1 & 133.0 & 174.5 & 66.04 & 19.6 & 139.5 \\
\hline PE/20ŁK & 112.5 & -159.2 & 132.6 & 156.4 & 66.59 & 20.1 & 140.4 \\
\hline
\end{tabular}

Table 2. Results of the DSC analysis of prepared materials. 
Except for the temperatures of phase transitions, their enthalpy values $\left(\Delta \mathrm{H}_{\mathrm{C}}\right.$ and $\Delta \mathrm{H}_{\mathrm{m}}$ ) were determined. Clearly, their absolute values decrease with filler loading, which is associated with the reduced content of polymer material. Nevertheless, the recorded values were higher than theoretical ones calculated based on enthalpies for neat polyethylene and its content in particular samples, as shown in Figure 6. Such an effect confirms the decrease of the supercooling parameter and points to the increased nucleating activity. As a result, an increase in the degree of crystallinity in the presented composites was observed.

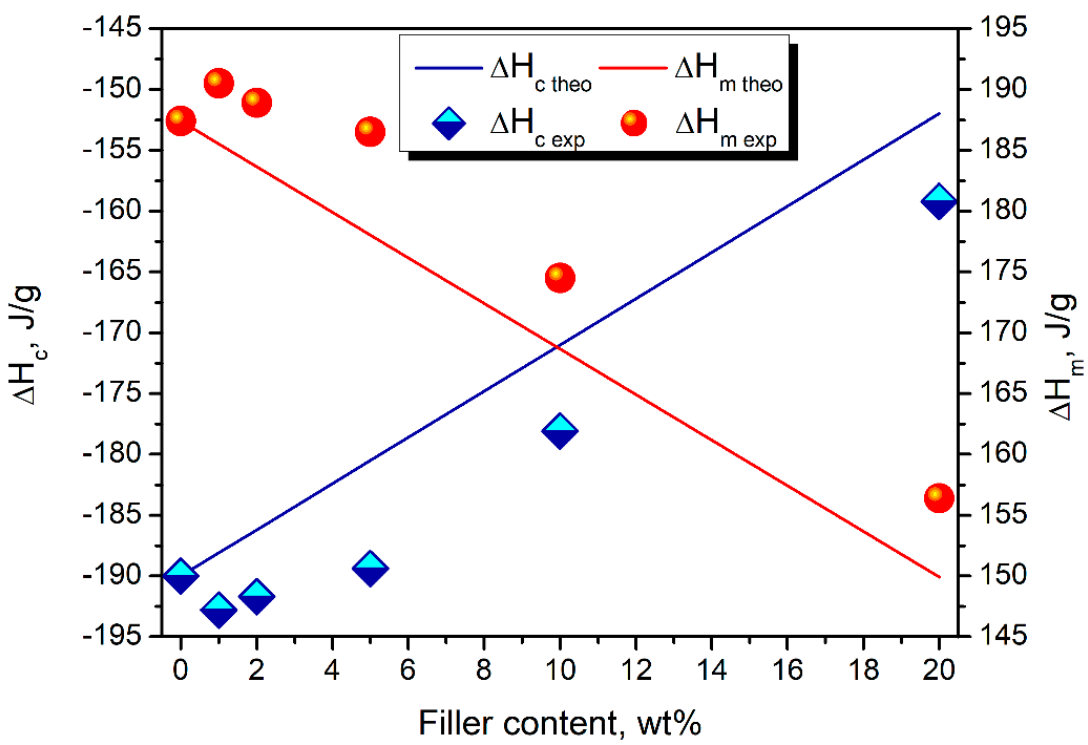

Figure 6. The impact of filler content on the crystallization and melting enthalpies of prepared composites.

Differential scanning calorimetry was also applied to evaluate the potential effects related to the antioxidant activity of coffee silverskin. Table 2 presents the values of the oxidation induction times for prepared composites, which can be used to determine the material's thermo-oxidative stability. Clearly, the OIT values were noticeably increased, which points to the very high antioxidant activity of coffee silverskin related to the content of caffeine, polyphenols, tannins, or melanoidins generated during roasting of coffee [58]. It can be seen that even at $1 \mathrm{wt} \%$ loading of coffee silverskin, the value of OIT was increased by $150 \%$ compared to neat PE. Higher filler contents resulted in further elongation of OIT, but for the materials containing over $5 \mathrm{wt} \%$ of $€ \mathrm{~K}$, the increase was not so significant. Nevertheless, the results are very promising, and the influence of coffee silverskin on the thermo-oxidative stability of analyzed composites would be investigated in further studies.

\section{Conclusions}

In the presented paper, we aimed to investigate the impact of coffee silverskin on polyethylene-based composites' processing and performance. Generally, the static and dynamic mechanical test results indicate that coffee silverskin should be introduced preferably in amounts not exceeding $2 \mathrm{wt} \%$, which indicates the enhancement of the PE matrix's tensile strength. The incorporation of $5 \mathrm{wt} \%$ did not cause the reinforcing effect but enabled the maintenance of polyethylene's tensile strength. Calculated values of the constrained chain volume and adhesion factor indicate relatively good interfacial adhesion at lower silverskin loadings. Nevertheless, even at the lowest loadings, the incorporation of coffee silverskin affected the material's continuity and ductility, significantly decreasing the elongation at break and reducing materials toughness. In the case of $5 \mathrm{wt} \%$ loading, a slight deterioration is noted, but composites show similar strength to the neat matrix. Higher loadings result in the noticeable deterioration of mechanical performance. Detailed analysis indicated the deterioration of the interfacial adhesion, probably caused by the 
agglomeration of filler particles, which confirms the significant rise of melt viscosity and reduction of flowability. The restrictions in molecular motions of polyethylene chains were also confirmed by the decrease in the melting temperature and supercooling parameter, which pointed to the reduced crystallite size and enhanced nucleating activity of coffee silverskin particles. Such an effect was confirmed by the slight increase in crystallization degree, up to $5 \%$. Nevertheless, the most exciting and promising effect of coffee silverskin incorporation was related to the massive elongation of oxidation induction time. The introduction of only $1 \mathrm{wt} \%$ of this filler caused the OIT increase from 20 to almost $55 \mathrm{~min}$. Higher contents of 2 and $5 \mathrm{wt} \%$ resulted in OIT values of 83.9 and $131.9 \mathrm{~min}$, respectively.

Concluding, coffee silverskin seems to be a very auspicious filler for polymer composites, which may be introduced at relatively low loadings, significantly enhancing the thermo-oxidative stability of material without deterioration of mechanical performance. Further studies associated with this filler should be focused on evaluating changes in processing, structure, mechanical, and thermal properties of composites subjected to accelerated aging tests. Moreover, combinations of coffee silverskin with other fillers, which may provide the reinforcing effect at higher loadings, seem to be an auspicious research direction.

Author Contributions: Conceptualization, A.H. and M.B.; methodology, M.B. and P.K.; software, P.K.; validation, A.H., M.B., and O.M.; formal analysis, A.H.; investigation, P.K. and O.M.; resources, A.H. and M.B.; data curation, P.K.; writing—original draft preparation, A.H.; writing-review and editing, M.B., O.M., and A.K.; visualization, A.H. and A.K.; supervision, A.H.; project administration, M.B. All authors have read and agreed to the published version of the manuscript.

Funding: This research received no external funding.

Institutional Review Board Statement: Not applicable.

Informed Consent Statement: Not applicable.

Data Availability Statement: Data is contained within the article. The data presented in this study are available in Coffee Silverskin as a Multifunctional Waste Filler for High-Density Polyethylene Green Composites.

Conflicts of Interest: The authors declare no conflict of interest.

\section{References}

1. Food Wastage: Key Facts and Figures. Available online: http://www.fao.org/news/story/en/item/196402/icode/ (accessed on 31 December 2020).

2. Lynch, K.M.; Steffen, E.J.; Arendt, E.K. Brewers' spent grain: A review with an emphasis on food and health. J. Inst. Brew. 2016, 122, 553-568. [CrossRef]

3. Blinová, L.; Sirotiak, M.; Bartošová, A.; Soldán, M. Review: Utilization of Waste From Coffee Production. Res. Pap. Fac. Mater. Sci. Technol. Slovak Univ. Technol. 2017, 25, 91-101. [CrossRef]

4. Esquivel, P.; Jiménez, V.M. Functional properties of coffee and coffee by-products. Food Res. Int. 2012, 46, 488-495. [CrossRef]

5. Adams, M.R.; Dougan, J. Waste Products. In Coffee; Clarke, R.J., Macrae, R., Eds.; Springer: Dordrecht, The Netherlands, 1987; pp. 257-291. [CrossRef]

6. Bharat Helkar, P.; Sahoo, A. Review: Food Industry By-Products used as a Functional Food Ingredients. Int. J. Waste Resour. 2016, 6, 1000248. [CrossRef]

7. Leal, H.A.; Babetto, A.S.; Bonse, B.C. Properties of lignocellulosic composites of coffee husk filled polypropylene. AIP Conf. Proc. 2020, 2205, 020072. [CrossRef]

8. Wojnowska-Baryła, I.; Kulikowska, D.; Bernat, K. Effect of Bio-Based Products on Waste Management. Sustainability 2020, 12, 2088. [CrossRef]

9. Mazur, K.; Jakubowska, P.; Romańska, P.; Kuciel, S. Green high density polyethylene (HDPE) reinforced with basalt fiber and agricultural fillers for technical applications. Compos. Part B Eng. 2020, 202, 108399. [CrossRef]

10. Bazan, P.; Mierzwiński, D.; Bogucki, R.; Kuciel, S. Bio-Based Polyethylene Composites with Natural Fiber: Mechanical, Thermal, and Ageing Properties. Materials 2020, 13, 2595. [CrossRef]

11. Tsang, Y.F.; Kumar, V.; Samadar, P.; Yang, Y.; Lee, J.; Ok, Y.S.; Song, H.; Kim, K.H.; Kwon, E.E.; Jeon, Y.J. Production of bioplastic through food waste valorization. Environ. Int. 2019, 127, 625-644. [CrossRef]

12. Sanchez-Vazquez, S.A.; Hailes, H.C.; Evans, J.R.G. Hydrophobic Polymers from Food Waste: Resources and Synthesis. Polym. Rev. 2013, 53, 627-694. [CrossRef] 
13. Jaisan, C.; Punbusayakul, N. Development of Coffee Pulp Extract-Incorporated Chitosan Film and Its Antimicrobial and Antioxidant Activities. KKU Res. J. 2016, 21, 140-149. [CrossRef]

14. Mirón-Mérida, V.A.; Yáñez-Fernández, J.; Montañez-Barragán, B.; Barragán Huerta, B.E. Valorization of coffee parchment waste (Coffea arabica) as a source of caffeine and phenolic compounds in antifungal gellan gum films. LWT-Food Sci. Technol. 2019, 101, 167-174. [CrossRef]

15. Garcia-Serna, E.; Martinez-Saez, N.; Mesias, M.; Morales, F.J.; del Castillo, M.D. Use of Coffee Silverskin and Stevia to Improve the Formulation of Biscuits. Pol. J. Food Nutr. Sci. 2014, 64, 243-251. [CrossRef]

16. Narita, Y.; Inouye, K. Review on utilization and composition of coffee silverskin. Food Res. Int. 2014, 61, 16-22. [CrossRef]

17. Ballesteros, L.F.; Teixeira, J.A.; Mussatto, S.I. Chemical, Functional, and Structural Properties of Spent Coffee Grounds and Coffee Silverskin. Food Bioprocess Technol. 2014, 7, 3493-3503. [CrossRef]

18. Conde, T.; Mussatto, S.I. Isolation of polyphenols from spent coffee grounds and silverskin by mild hydrothermal pretreatment. Prep. Biochem. Biotechnol. 2015, 46, 406-409. [CrossRef] [PubMed]

19. Moraczewski, K.; Stepczyńska, M.; Malinowski, R.; Karasiewicz, T.; Jagodziński, B.; Rytlewski, P. The Effect of Accelerated Aging on Polylactide Containing Plant Extracts. Polymers 2019, 11, 575. [CrossRef]

20. Ochoa, D.; Rojas-Vargas, J.; Costa, Y. Characterization of NaOH-Treated Colombian Silverskin Coffee Fiber as a Composite Reinforcement. BioResources 2017, 12, 8803-8812.

21. Dominici, F.; García García, D.; Fombuena, V.; Luzi, F.; Puglia, D.; Torre, L.; Balart, R. Bio-Polyethylene-Based Composites Reinforced with Alkali and Palmitoyl Chloride-Treated Coffee Silverskin. Molecules 2019, 24, 3113. [CrossRef]

22. Sarasini, F.; Luzi, F.; Dominici, F.; Maffei, G.; Iannone, A.; Zuorro, A.; Lavecchia, R.; Torre, L.; Carbonell-Verdu, A.; Balart, R.; et al. Effect of Different Compatibilizers on Sustainable Composites Based on a PHBV/PBAT Matrix Filled with Coffee Silverskin. Polymers 2018, 10, 1256. [CrossRef]

23. Totaro, G.; Sisti, L.; Fiorini, M.; Lancellotti, I.; Andreola, F.N.; Saccani, A. Formulation of Green Particulate Composites from PLA and PBS Matrix and Wastes Deriving from the Coffee Production. J. Polym. Environ. 2019, 27, 1488-1496. [CrossRef]

24. Zarrinbakhsh, N.; Wang, T.; Rodriguez-Uribe, A.; Misra, M.; Mohanty, A.K. Characterization of wastes and coproducts from the coffee industry for composite material production. BioResources 2016, 11, 7637-7653. [CrossRef]

25. Sarasini, F.; Tirillò, J.; Zuorro, A.; Maffei, G.; Lavecchia, R.; Puglia, D.; Dominici, F.; Luzi, F.; Valente, T.; Torre, L. Recycling coffee silverskin in sustainable composites based on a poly(butylene adipate-co-terephthalate)/poly(3-hydroxybutyrate-co-3hydroxyvalerate) matrix. Ind. Crop. Prod. 2018, 118, 311-320. [CrossRef]

26. Hejna, A. Potential applications of by-products from the coffee industry inpolymer technology—Current state and perspectives. Waste Manag. 2021, 121, 296-330. [CrossRef] [PubMed]

27. Behrouzian, F.; Amini, A.M.; Alghooneh, A.; Razavi, S.M.A. Characterization of dietary fiber from coffee silverskin: An optimization study using response surface methodology. Bioact. Carbohydr. Diet. Fibre 2016, 8, 58-64. [CrossRef]

28. Costa, A.S.G.; Alves, R.C.; Vinha, A.F.; Costa, E.; Costa, C.S.G.; Nunes, M.A.; Almeida, A.A.; Santos-Silva, A.; Oliveira, M.B.P.P. Nutritional, chemical and antioxidant/pro-oxidant profiles of silverskin, a coffee roasting by-product. Food Chem. 2018, 267, 28-35. [CrossRef]

29. Toschi, T.G.; Cardenia, V.; Bonaga, G.; Mandrioli, M.; Rodriguez-Estrada, M.T. Coffee Silverskin: Characterization, Possible Uses, and Safety Aspects. J. Agric. Food Chem. 2014, 62, 10836-10844. [CrossRef]

30. Napolitano, A.; Fogliano, V.; Tafuri, A.; Ritieni, A. Natural occurrence of ochratoxin A and antioxidant activities of green and roasted coffees and corresponding byproducts. J. Agric. Food Chem. 2007, 55, 10499-10504. [CrossRef]

31. Ateş, G.; Elmac1, Y. Physical, chemical and sensory characteristics of fiber-enriched cakes prepared with coffee silverskin as wheat flour substitution. Food Meas. 2019, 13, 755-763. [CrossRef]

32. Janissen, B.; Huynh, T. Chemical composition and value-adding applications of coffee industry by-products: A review. Resour. Conserv. Recycl. 2018, 128, 110-117. [CrossRef]

33. Mysiukiewicz, O.; Barczewski, M.; Skórczewska, K.; Matykiewicz, D. Correlation between processing parameters and degradation of different polylactide grades during twin-screw extrusion. Polymers 2020, 12, 1333. [CrossRef] [PubMed]

34. Mirabella, F.M.; Bafna, A. Determination of the crystallinity of polyethylene/?-olefin copolymers by thermal analysis: Relationship of the heat of fusion of $100 \%$ polyethylene crystal and the density. J. Polym. Sci. Pol. Phys. 2002, 40, 1637-1643. [CrossRef]

35. Qiu, W.; Zhang, F.; Endo, T.; Hirotsu, T. Isocyanate as a compatibilizing agent on the properties of highly crystalline cellulose/polypropylene composites. J. Mater. Sci. 2005, 40, 3607-3614. [CrossRef]

36. Kloziński, A.; Barczewski, M. Comparison of off-line, on-line and in-line measuring techniques used for determining the rheological characteristics of polyethylene composites with calcium carbonate. Polimery 2019, 64, 83-92. [CrossRef]

37. Hejna, A.; Formela, K.; Saeb, M.R. Processing, mechanical and thermal behavior assessments of polycaprolactone/agricultural wastes biocomposites. Ind. Crop. Prod. 2015, 76, 725-733. [CrossRef]

38. D'Antò, V.; Muraglie, S.; Castellano, B.; Candida, E.; Sfondrini, M.F.; Scribante, A.; Grippaudo, C. Influence of Dental Composite Viscosity in Attachment Reproduction: An Experimental in Vitro Study. Materials 2019, 12, 4001. [CrossRef]

39. Aranguren, M.I.; Mora, E.; DeGroot, J.V.; Macosko, C.W. Effect of reinforcing fillers on the rheology of polymer melts. J. Rheol. 1992, 36, 1165-1182. [CrossRef]

40. Mysiukiewicz, O.; Kosmela, P.; Barczewski, M.; Hejna, A. Mechanical, Thermal and Rheological Properties of Polyethylene-Based Composites Filled with Micrometric Aluminum Powder. Materials 2020, 13, 1242. [CrossRef] 
41. Gent, M.R.; Menendez, M.; Toraño, J.; Diego, I. Recycling of plastic waste by density separation: Prospects for optimization. Waste Manag. Res. 2009, 27, 175-187. [CrossRef]

42. Mehdikhani, M.; Gorbatikh, L.; Verpoest, I.; Lomov, S.V. Voids in fiber-reinforced polymer composites: A review on their formation, characteristics, and effects on mechanical performance. J. Compos. Mater. 2018, 002199831877215. [CrossRef]

43. Keskisaari, A.; Butylina, S.; Kärki, T. Use of construction and demolition wastes as mineral fillers in hybrid wood-polymer composites. J. Appl. Polym. Sci. 2016, 133, 43412. [CrossRef]

44. Salasinska, K.; Polka, M.; Gloc, M.; Ryszkowska, J. Natural fiber composites: The effect of the kind and content of filler on the dimensional and fire stability of polyolefin-based composites. Polimery 2016, 61, 255-265. [CrossRef]

45. Birt, E.A.; Smith, R.A. A review of NDE methods for porosity measurement in fibre-reinforced polymer composites. Insight Non-Destr. Test. Cond. Monit. 2004, 46, 681-686. [CrossRef]

46. Michalska-Pożoga, I.; Rydzkowski, T. The effect of extrusion conditions for a screw-disk plasticizing system on the mechanical properties of wood-polymer composites (WPC). Polimery 2016, 61, 202-212. [CrossRef]

47. Chan, C.; Vandi, L.J.; Pratt, S.; Halley, P.; Richardson, D.; Werker, A.; Laycock, B. Processing and characterisation of polyhydroxyalkanoate (PHA)-based wood plastic composites: Effect of non-reactive additives. Appita J. 2016, 69, 352-360.

48. Perkins, W.G. Polymer toughness and impact resistance. Polym. Eng. Sci. 1999, 39, 2445-2460. [CrossRef]

49. Barczewski, M.; Szostak, M.; Nowak, D.; Piasecki, A. Effect of wood flour addition and modification of its surface on the properties of rotationally molded polypropylene composites. Polimery 2018, 63, 772-784. [CrossRef]

50. Brostow, W.; Hagg Lobland, H.E.; Narkis, M. Sliding wear, viscoelasticity, and brittleness of polymers. J. Mater. Res. 2006, 21, 2422-2428. [CrossRef]

51. Galeja, M.; Hejna, A.; Kosmela, P.; Kulawik, A. Static and Dynamic Mechanical Properties of 3D Printed ABS as a Function of Raster Angle. Materials 2020, 13, 297. [CrossRef]

52. Brostow, W.; Hagg Lobland, H.E.; Khoja, S. Brittleness and toughness of polymers and other materials. Mater. Lett. 2015, 159, 478-480. [CrossRef]

53. Abdalla, M.; Dean, D.; Adibempe, D.; Nyairo, E.; Robinson, P.; Thompson, G. The effect of interfacial chemistry on molecular mobility and morphology of multiwalled carbon nanotubes epoxy nanocomposite. Polymer 2007, 48, 5662-5670. [CrossRef]

54. Kubát, J.; Rigdahl, M.; Welander, M. Characterization of interfacial interactions in high density polyethylene filled with glass spheres using dynamic-mechanical analysis. J. Appl. Polym. Sci. 1990, 39, 1527-1539. [CrossRef]

55. Bindu, P.; Thomas, S. Viscoelastic Behavior and Reinforcement Mechanism in Rubber Nanocomposites in the Vicinity of Spherical Nanoparticles. J. Phys. Chem. B 2013, 117, 12632-12648. [CrossRef] [PubMed]

56. Zhou, W. Thermal and Dielectric Properties of the Aluminum Particle Reinforced Linear Low-Density Polyethylene Composites. Polym. Eng. Sci. 2011, 51, 917-924. [CrossRef]

57. Hejna, A.; Kosmela, P. Insights into Compatibilization of Poly( $\varepsilon$-caprolactone)-based Biocomposites with Diisocyanates as Modifiers of Cellulose Fillers. Mindanao J. Sci. Technol. 2020, 18, 221-241.

58. Hejna, A.; Barczewski, M.; Kosmela, P.; Mysiukiewicz, O. Inhibition of Polymer Photodegradation by Incorporation of Coffee Silverskin. Proceedings 2020, 4, 7219. [CrossRef] 